\title{
DO ANTES AO DEPOIS: A INFLUÊNCIA DA LUMBER COMPANY PARA A DEFLAGRAÇÃO DO MOVIMENTO SERTANEJO DO CONTESTADO E SEU IMPACTO NA REGIÃO FRONTEIRIÇA ENTRE PARANÁ E SANTA CATARINA
}

\author{
FROM BEFORE TO AFTER: THE LUMBER'S COMPANY \\ INFLUENCES IN THE OUTBREAK OF CONTESTADO'S \\ MOVEMENT AND ITS IMPACT IN THE FRONTIER \\ REGION BETWEEN PARANÁ AND SANTA CATARINA
}

Alexandre Assis Tomporoski*

\begin{abstract}
Resumo: O texto que segue desenvolve-se a partir de três eixos principais, tendo como referência a atuação da Southern Brazil Lumber and Colonization Company na região de Três Barras, no planalto contestado. O primeiro deles analisa o período anterior ao advento da companhia, elucidando a formação do modo de vida do sertanejo através de suas práticas e costumes. O segundo eixo analisa o impacto resultante da instalação da empresa e as peculiaridades desse processo, tal como a expulsão dos posseiros das terras recebidas pela companhia, o que contribuiu diretamente para a deflagração do movimento sertanejo do Contestado (1912-1916). O terceiro ilumina o período posterior ao movimento, focalizando nas implicações decorrentes a manutenção das atividades operacionais da companhia pelas décadas subsequentes, tais como a atuação de seus trabalhadores e os embates políticos nos quais a empresa tomou parte. Ainda será contemplado o processo de estatização da companhia e a sua transformação em um campo de manobras do exército nacional, na década de 1950, em meio a outro violento procedimento de desapropriação de terras.

Palavras-chave: Lumber Company. Contestado. Trabalhadores. Campo de
\end{abstract} Instrução.

* Professor na Universidade do Contestado (UnC). E-mail: assis.historia@gmail.com 


\begin{abstract}
The followed text has been developed since three principal pivots, having as references the actions of Southern Brazil Lumber and Colonization Company in the Três Barras region, in the Contestado's Upland. The first one analyses the period before the company's advent, to elucidate the creation of inlander's life style through his practices and customs. The second pivot analyses the resulted impact of company's installation and the peculiarities of this process, like the land's owners expulsion, received by company, which accredited directly for the Contestado's Movement outbreak. The third one shows the results of the research that has been developed, which help to illuminate the period before the movement, focus in the implications of its permanence in the region for the next decades, like the worker's actions and the politic's collision, which the company took part. Even will be contemplate the company's state control process, and its transformation in a national army camp, in the fifties of twentieth century, while another violent land's dispossess procedure.
\end{abstract}

Keywords: Lumber Company. Contestado. Workers. Training camp.

Transcorridos cem anos desde o início do movimento sertanejo do Contestado, os pesquisadores regozijam-se pelo impulso que os estudos sobre o tema receberam nas últimas décadas. O número de inscritos e a diversidade de temas abordados, nos trabalhos apresentados em encontros que marcam esse momento de reflexão, corroboram esse otimismo.

$\mathrm{O}$ avanço das pesquisas expôs a complexidade do movimento, com suas especificidades e a heterogeneidade de suas causas. Não obstante, ainda permanece em aberto um profícuo campo de estudo, concernente ao legado daquele processo histórico para a região, os 'despojos' da guerra que ainda afetam a vida de milhares de pessoas. Dentre as causas fundamentais para o início do movimento sertanejo - cujas consequências ainda se manifestam hodiernamente aos moradores do planalto contestado ${ }^{1}$ - podemos elencar o advento e a instalação de companhias estrangeiras dos setores ferroviário e madeireiro. Ambas, municiadas com a típica voracidade do capital, avançaram sobre a região, devorando árvores, vidas e a esperança de milhares de pessoas pobres - do interior do planalto meridional brasileiro - de que era possível viver em um mundo com justiça e igualdade.

Nas páginas que seguem, com o intuito de reconstruir parte desse processo, inicialmente examinaremos o modo de vida do sertanejo pobre da região, no período anterior à instalação das empresas e ao início do conflito armado. Esse modo de vida, marcado por costumes e práticas que valorizavam as relações solidárias e coletivas, foi afetado diretamente pela construção da ferrovia e pela instalação da Southern Brazil Lumber and Colonization Company. No princípio, os pobres resistiram à desestruturação de sua forma de 
viver, impactada pelas novas relações advindas das atividades desenvolvidas pelas empresas, o que contribuiu para o agravamento dos problemas e das tensões sociais no planalto, elevando a adesão às fileiras do movimento sertanejo; depois, impuseram-se aos abusos praticados pela companhia contra seus trabalhadores, também pobres do planalto ou imigrantes ali instalados, os quais compartilhavam desse modo de vida acaboclado.

Além dos impactos sobre o modo de vida do sertanejo, o presente trabalho também abordará a atuação política da companhia, as consequências de sua presença na região por mais de cinco décadas, bem como sua transferência para o Ministério da Guerra e posterior transformação num campo de manobras do exército brasileiro.

Dessa forma, a análise não se restringirá apenas ao período no qual se desenvolveu o movimento sertanejo do Contestado, abrangendo, também, o período de atuação da Lumber Company.

\section{A REGIÃO DO PLANALTO ANTES DA LUMBER}

A região do planalto catarinense tem sua configuração ligada à Estrada de Tropas, caminho através do qual os tropeiros conduziam gado e mulas do interior do Rio Grande do Sul até São Paulo, para comercialização na feira de Sorocaba. Muitas das cidades da região surgiram como pequenos locais de parada da tropa e, paulatinamente, transformaram-se em vilas e cidades.

Outro elemento que fomentou a fundação de núcleos populacionais foi a longa disputa de limites entre os estados do Paraná e Santa Catarina, os quais, com o intuito de assegurar ao menos o controle provisório sobre a região fronteiriça, estimularam a criação de distritos e municípios.

De modo geral, os moradores dessas vilas e cidades compunham um tipo étnico não muito preciso, denominado "caboclo" ou "sertanejo", o qual pode ser mais apropriadamente percebido se caracterizado não apenas pela simples ideia de mistura étnica entre indígenas e descendentes de lusos, mas também ao considerar seu modo de vida, tradições e costumes. A região possuía contingentes consideráveis de população negra e mestiça, o tropeiro de origem paranaense ou sul rio-grandense, além, é claro, dos significativos grupos de imigrantes que ocuparam a região a partir do final do século XIX e início do século XX, tais como alemães, austríacos, espanhóis, galeses, holandeses, poloneses, portugueses, russos e ucranianos. As primeiras levas de imigrantes que chegaram à região, ainda no século XIX, tenderam a amalgamar-se à população local, quando muitos imigrantes e descendentes passaram a adotar o mesmo modo de vida da população pobre nacional, num processo de acaboclamento. ${ }^{2}$ 
O modo de vida do homem pobre do planalto dependia primeiramente do apossamento da terra. Na sua posse construía seu rancho com as próprias mãos e com a madeira do entorno. Nos fundos constituía uma pequena roça cabocla, com variadas culturas, o que lhe assegurava certa porção de alimento durante praticamente todo o ano, juntamente com algumas espécies de árvores frutíferas que, ao lado do pinhão no inverno, suplementavam sua alimentação. Criava alguns pequenos animais - galinhas e porcos principalmente - mais algum cachorro de estimação para ajudar na caçada. Conservava uma arma, se possível um rifle winchester, para a caça abundante e a proteção de sua posse, de sua honra e de sua vida. A partir do mês de junho começava a fazer erva, ou seja, coletar a erva mate do erval nativo disponível mais próximo. Tanto o pouco que sobrava de sua roça, quanto a erva extraída, eram negociados - através de troca - com os bodegueiros da localidade ou com os tropeiros que cortavam a região. O objetivo era adquirir produtos essenciais: sal, para conservar a carne; pólvora para ativar o rifle; querosene para iluminar o rancho e cachaça para aquecer a alma.

Assim, o habitante da região mantinha um modo de vida que dependia da agricultura, da criação de animais e da exploração das matas, mediante o corte da erva mate nativa ou da coleta do pinhão (semente da araucária), atividade que até hoje mobiliza a população mais pobre que o comercializa em pequenas quantidades visando o complemento da renda. Evidentemente, a cultura dos pobres do planalto catarinense tinha como elemento essencial o trabalho. Lidar na roça cabocla, fazer erva, derrubar madeira, caçar ou pescar, consistiam em atividades que permitiam a sobrevivência dos sertanejos e exigiam perícia no domínio de ferramentas e armas. Para esta exploração dos mínimos vitais, as virtudes pessoais e a destreza no manuseio das ferramentas utilizadas no dia a dia, constituíram um conhecimento prático acerca da utilização de certas armas. O uso de machados, facões e facas estava ligado ao corte da erva mate, à lida com o gado e à exploração da floresta. Logo, o uso desses instrumentos, parte inseparável da indumentária do sertanejo, rendeu-lhe extrema habilidade na lida com armas brancas. Exemplo disso são os diversos confrontos vencidos pelos sertanejos rebelados contra as forças legais no período da Guerra do Contestado (1912-1916), quando aqueles optaram pelo 'entrevero', ou seja, o confronto direto com arma branca. O conhecimento sobre como tais atividades deveriam ser desenvolvidas era transmitido oralmente. Nesse processo, nessas trocas, outras formas de conhecimento eram transmitidas: experiências sociais compartilhadas pela comunidade, práticas aceitas e repreendidas, bem como as noções aceitas e praticadas coletivamente pelos membros daquele grupo. Tais costumes transmitidos pela oralidade se espraiaram pelas gerações. Eram importantes numa ampla região, muito além do planalto catarinense e sul do Paraná, desde a região do Prata até o interior de São Paulo, ou seja, atingindo uma extensa faixa territorial. 
Nas localidades do interior do planalto Contestado, aonde residia a maior parte da população, as necessidades de sobrevivência fomentaram práticas que congregavam grande número de vizinhos. Essas atividades, que ofereciam a possibilidade de auxílio mútuo, também contribuíam para a definição dos limites daquelas localidades. É plausível considerarmos que a ocupação de todo o planalto catarinense decorreu da formação do que podemos chamar de bairros rurais. ${ }^{3} \mathrm{O}$ bairro rural era o agrupamento de algumas ou muitas famílias cuja conexão não se caracterizava apenas pela proximidade. As habitações poderiam estar bastante próximas, tal qual um povoado, ou tão afastadas que o observador não conseguiria perceber que compunham algo unificado. Ali estavam intercaladas pequenas lavouras de subsistência, uma mata de araucárias e pequenas casas. Não obstante a proximidade entre as moradias, os elementos que congregavam aquelas pessoas estavam conectados à vida social e cultural. Os habitantes do bairro rural construíam seus vínculos pela convivência, pela necessidade de auxílio mútuo para os trabalhos árduos e urgentes, bem como pelo compartilhamento dos momentos lúdicos e religiosos. ${ }^{4}$

Nesse contexto,integrava um determinado bairro rural aquele indivíduo que era convocado para atividades de auxílio aos vizinhos e que, quando necessário, também possuía legitimidade para realizar a convocação. As atividades de auxílio mútuo são comuns em diferentes regiões e épocas, especialmente entre as camadas mais pobres da população, às quais, obviamente, mais necessitam de auxílio para garantir a sobrevivência, o que resulta no fortalecimento dos laços de solidariedade horizontais. Comumente denominado de mutirão, na região do planalto catarinense recebeu o nome de pixirum ou pixuru:

Os trabalhos da roçada costumam-se fazer por volta de junho - o que tem o inconveniente de coincidir com a época mais própria para o corte do mate, porém, é o tempo melhor para abater a floresta. Se se trata de uma tarefa abrumadora para um homem só, acontece ao sertanejo de Serra Acima recorrer, como em outras partes do Brasil, ao trabalho amigo e voluntário dos vizinhos. O ajutório aqui se denomina pixuru: vinte ou trinta homens, animados pelo espírito de cooperar, entre ditos chistosos e cantorias, deitam abaixo num só dia, alegremente, coisa como dois alqueires de mata. ${ }^{5}$

O pixirum - denominação aqui adotada por consistir na mais comumente encontrada nas últimas décadas na região em tela, onde também se popularizou a nomenclatura "troca de dia" para as atividades de auxílio mútuo - permitia que tarefas praticamente impossíveis para um único homem pudessem ser realizadas em poucos dias, como a construção de casas ou galpões. Porém, 
a convocação do pixirum ocorria comumente para a execução de roçadas, limpezas de terrenos e colheitas. Contudo, mesmo práticas não relacionadas diretamente ao trabalho eram acionadas, tais como a divisão da carne de animais abatidos entre os vizinhos, que retribuíam a gentileza, ou ainda a socialização de poços e nascentes em época de secas.

Essas práticas irrigavam laços de confiança e alimentavam redes de cooperação, representando um recurso fundamental para os indivíduos que as exerciam, cujos benefícios eram compartilhados por todos os integrantes do grupo, fortalecendo seus laços e relações de solidariedade.

A capacidade das pessoas cooperarem, confiarem em seus vizinhos e estabelecerem laços horizontais de participação, demonstra a valorização desse atributo naquela sociedade. Porém, a cooperação voluntária, assentada na confiança, só é possível em sociedades que convivem com regras de reciprocidade, o que fomenta a cooperação espontânea. No caso do pixirum, convocar e ser convocado significava ter legitimidade perante aquela comunidade e a peça principal dessa engrenagem consistia no princípio da obrigação mútua, ou seja, aquele vizinho que fora beneficiado pelo trabalho dos membros do bairro rural deveria retribuir a ajuda, atendendo imediatamente ao chamado para outras tarefas. A obrigação moral de retribuir imediatamente à convocação realizada pelas pessoas que o ajudaram anteriormente, determinava a formação de uma ampla rede de relações de vizinhança, interconectando os moradores do bairro rural. Esse sistema fomentava o desenvolvimento de uma consciência coletiva: todos juntos formavam um único grupo, e seu eficiente funcionamento dependia da participação de todos. A ausência de qualquer forma de remuneração pelo serviço reforçava valores não econômicos, solidificando a importância da colaboração solidária. Além disso, nessas formas de participação, cada indivíduo tem um grau de importância e de pertencimento relativamente igual, o que possibilita o aumento da confiança e permite futuras colaborações. Nas sociedades em que o auxílio mútuo, a colaboração contínua e a cooperação são fundamentais para a subsistência dos mais pobres, essas relações são regidas por um contrato moral, promovendo a sinergia da rede de cooperação, pois confiar e usufruir das vantagens de confiar produz mais confiança.

Portanto, o trabalho coletivo consistia num fator relevante para a população pobre do planalto, sendo razoável supormos que os elementos de solidariedade que envolviam o pixirum pudessem romper ou amenizar certas barreiras, inclusive de caráter étnico. As diferenças entre indivíduos de grupos étnicos distintos poderiam ser suplantadas pela necessidade de ajuda para o trabalho e mesmo pela noção de solidariedade. Como os pixiruns reuniam praticamente as mesmas pessoas diversas vezes ao longo do ano, a tendência era de uma aproximação entre os integrantes do bairro. 
Uma demonstração do potencial mobilizador que o pixirum propiciava aos moradores do bairro rural resulta do fato de que, amiúde, o sertanejo não convocava os vizinhos por não ter condições de oferecer alimentação a todos ou promover uma festa de encerramento, norma elementar para a organização do pixirum. Em alguns desses casos, os vizinhos, ao perceberem que ele estava "apurado", ou seja, sobrecarregado de tarefas, combinavam entre si para ajudá-lo, sem avisar com antecipação. Não havia convocação, a motivação para auxiliar era espontânea.

Contudo, não podemos considerar que essas reuniões de trabalho coletivo caracterizavam o "paraíso" da conciliação étnica e fossem o berço de uma sólida formação pacífica entre todos. O conflito - antítese e componente das relações de solidariedade - também emergia e isto não era incomum. O mutirão e o congraçamento pelo seu encerramento, assim como as festas religiosas, eram ocasiões nas quais o conflito emergia, muitas vezes reavivando antigas querelas entre os integrantes da vizinhança. De todo modo, aqui optou-se por destacar as características solidárias desse universo. ${ }^{6}$

As disputas e conflitos encontravam ambiente propício para seu desenvolvimento nas atividades lúdicas que ocorriam após o mutirão. Durante a tarefa, o beneficiário deveria fornecer alimentação necessária para o grupo e, após o término dos trabalhos, promover uma celebração festiva. Dependendo das condições materiais do indivíduo que convocou o mutirão, bem como do número de vizinhos envolvidos na execução das tarefas, essa celebração poderia consistir numa simples garrafa de cachaça - sorvida na bodega mais próxima ou sob as sombras de uma árvore nas adjacências do local onde o trabalho fora desenvolvido - ou num baile, animado por gaita e violão e sem hora para terminar. Essa retribuição festiva representava um gesto de amizade, um momento de celebração pela cooperação eficiente e cujo significado transcendia a simples necessidade imediata de suplementação de mão de obra, construindo, fortalecendo e irrigando uma rede ampla de coletividade, que proporcionava aos participantes uma experiência social integradora.

Analogamente ao trabalho coletivo e à celebração festiva, as atividades religiosas representavam outro elemento definidor dos contornos e da configuração do bairro rural e, por conseguinte, do espaço habitado e transformado pelo sertanejo pobre do planalto catarinense.

A religião tem um papel importante como meio de preservação da sociabilidade. No planalto contestado, desenvolvia-se um conjunto de importantes práticas socioculturais que tinham por universo o grupo rural de vizinhança. Sendo assim, poder-se-ia definir os limites do bairro rural conforme a participação de seus habitantes nos festejos religiosos locais, quer fossem oficiais ou, inclusive, informais.

Podemos tomar como referência a devoção por São João Maria - que aconselhava os moradores da região a tratar a natureza com respeito e retirar 
dela apenas aquilo que fosse realmente necessário; orientava-os sobre como se relacionar harmoniosamente com a população indígena local, além de realizar críticas contumazes às práticas monetárias que desumanizavam os homens, ou seja, apresentava um discurso marcado por uma profunda racionalidade no trato com a natureza e com 'o outro', um discurso humanitário, preservacionista e anticapitalista, posicionamentos muito distintos daqueles que então repercutiam pela região, vinculadas às relações organizadas a partir do capital - e, mais tarde, por José Maria, que representavam práticas religiosas coletivas arraigadas ao modo de vida do morador do planalto e que fomentavam a proximidade, a sociabilidade e a união dos sertanejos, como a organização da "Santa Religião" e a deflagração do movimento de 1912-1916 demonstraram.

Nesse amplo e complexo processo histórico, marcado por demonstrações de solidariedade e por laços de união e coletividade, podemos identificar futuros contornos de classe. Evidentemente, na classe habitam tanto a divisão quanto a unidade, características que não são mutuamente excludentes. Os costumes e práticas, descritos anteriormente, estavam arraigados à vida do sertanejo e mostrar-se-iam empecilhos aos interesses econômicos que encontravam-se em processo incipiente na região do planalto contestado. Os protagonistas de tais práticas e costumes reagiriam aos ataques e cerceamentos impostos a eles, especialmente pelo avanço das forças capitalistas estrangeiras.

Através da reconstrução das ações dessas pessoas, podemos identificar a existência de uma racionalidade própria, a qual era definida pelos costumes. Portanto, entendemos que os indivíduos das classes subalternas conseguem resolver seus problemas e controlar suas vidas, de acordo com sua própria lógica, o que devolve aos pobres o direito de serem agentes de suas vidas. ${ }^{7}$

\section{OS POBRES DO PLANALTO CONTESTADO RESISTIRAM: O ADVENTO DAS EMPRESAS ESTRANGEIRAS}

O cenário reconstruído anteriormente nos oferece uma perspectiva da forma como a população pobre do planalto contestado vivia até o início do século XX. O modo de vida amparava-se em elementos fundamentais, como a relação com a natureza, a dependência de práticas coletivas para fomentar sua subsistência - a qual exigia o manuseio e domínio de ferramentas e armas - e o conhecimento profundo da região que habitava. As necessidades de sobrevivência aproximaram aquelas pessoas e estimularam a construção de laços de solidariedade.

Com a chegada das empresas estrangerias na região, esse modo de vida foi abruptamente afetado e obliterou. A partir de então, aquilo que o planaltino considerava 'seu', 'justo' ou 'um direito', deixou de ser respeitado. Isso determinou sua resistência, sua mobilização e sua luta, através da qual milhares 
de pessoas, que utilizaram todo o conhecimento construído coletivamente nas décadas anteriores - um tecido comum -, decidiram que suas características existenciais precedentes deveriam ser restauradas e, para isso, arriscaram e sacrificaram suas vidas.

O surgimento da Southern Brazil Lumber and Colonization Company está conectado ao processo de construção de uma ferrovia que interligaria os estados do sul do Brasil. Para a consecução desse propósito, o governo brasileiro estabeleceu contrato com a Brazil Railway Company, empresa responsável pela construção do caminho de ferro que cortou o planalto contestado, tendo como pontos de partida e de chegada as cidades de Sorocaba, em São Paulo, e de Santa Maria, no Rio Grande do Sul, respectivamente. A construção dessa linha férrea, que atravessou extensas regiões, afetou a vida das populações, aumentando o valor econômico das terras, agravando problemas sociais e influenciando diretamente na deflagração do movimento sertanejo do Contestado.

No mês de novembro de 1911, faltando menos de um ano para a batalha do Irani, marco inicial da Guerra do Contestado, a Estrada de Ferro São Paulo Rio Grande publicou um edital que proibia a 'invasão' e 'ocupação' de terrenos pertencentes à companhia, tanto nas margens do rio do Peixe, quanto em outras localidades onde, "por concessão estadual, a Companhia de Estrada de Ferro possui terras que já foram ou estão sendo medidas e demarcadas por ela". ${ }^{8}$ Aqueles posseiros que não aceitavam a determinação e continuavam ocupando as suas terras, agora de propriedade da companhia estrangeira, recebiam a visita do Corpo de Segurança da empresa, cujas práticas violentas eram bastante eficazes e representavam o modo como a população pobre nacional era tratada em casos de reintegração de posse.

O contrato para construção da ferrovia estabeleceu em seus dispositivos que a empresa responsável pela obra - a Brazil Railway Company - teria direito a explorar as terras adjacentes à linha tronco, em uma extensão de até quinze quilômetros para cada lado do leito da linha férrea. Em 1910, foi concluída a construção do trecho que rasgava o território catarinense, num total de trezentos e oitenta quilômetros, entre as cidades de União da Vitória, no Paraná e Marcelino Ramos, no Rio Grande do Sul. Sete anos mais tarde, o ramal que ligava União da Vitória e a cidade portuária de São Francisco do Sul, em Santa Catarina, foi concluído e colocado em funcionamento. A conclusão deste ramal permitiu o rápido escoamento da produção de madeira e erva mate do planalto contestado.

Aquelas terras eram cobertas por milhões de pinheiros araucária, imbuias, canelas e cedros. Objetivando serrar e exportar esta madeira de alto valor econômico e, mais tarde, vender parte das terras a imigrantes europeus, foi constituída uma subsidiária da Brazil Railway Company, a Southern Brazil Lumber and Colonization Company. Em 1910, a Lumber instalou em Três Barras, então território paranaense contestado por Santa Catarina, uma moderna serraria. ${ }^{9}$ 
A empresa instituiu um processo industrial com alto grau de mecanização e elevada organização técnica. A etapa inicial consistia no corte das toras no meio da floresta, tarefa realizada por grupos de trabalhadores que se embrenhavam nas matas, selecionavam e serravam as árvores. Em seguida, as toras que jaziam ao chão eram conectadas a cabos de aço com centenas de metros de comprimento e içadas por guinchos movidos a vapor comprimido. As toras gigantescas eram arrastadas até a margem dos ramais ferroviários construídos pela própria empresa, que poderiam atingir até trinta quilômetros de extensão. Ao serem arrastadas, destruíam toda a vegetação que estivesse em seu caminho, árvores menores, espécies economicamente menos interessantes e também grandes quantidades de árvores de erva mate, cuja extração - como já tivemos a oportunidade de analisar - consistia num elemento fundamental de sobrevivência para a população pobre que habitava a região. Após remover as toras até a beira dos trilhos, o mesmo guincho as erguia e as colocava sobre vagões que eram conduzidos até o engenho da serraria, no centro da vila de Três Barras. Dentro do engenho, as toras eram serradas, selecionadas e armazenadas mecanicamente. Em seguida, eram carregadas em vagões e transportadas até os portos de São Francisco do Sul e Paranaguá e dali enviadas ao exterior. ${ }^{10}$

O morador pobre do planalto, o caboclo ou sertanejo, ocupava aquelas terras pelo apossamento há muito tempo, inclusive, muitas vezes, há gerações. Conforme examinado anteriormente, ali construiu uma relação de exploração racional dos recursos naturais e teceu complexas relações sociais com seus pares. Todo esse universo gestado ao longo de décadas foi destruído de forma rápida, fria e impessoal, características da 'racionalidade' do capital.

Além desse terrível processo que ceifou a vida ou comprometeu a sobrevivência de milhares de pessoas, a atuação da ferrovia desestabilizou a organização econômica da população local. O Caminho de Tropas deixou de existir, o que gerou uma depressão econômica nas localidades demarcadas por casas comerciais e espaços próprios de pouso dos tropeiros - de descanso e de retomada de peso dos animais - antes de prosseguirem viagem em direção a São Paulo. Essa desestruturação econômica e seu impacto sobre o modo de vida sertanejo, também acarretou graves consequências para a sobrevivência daquela população.

Um processo de expulsão da população sertaneja que ocupava as terras transferidas ou ocupadas pela Lumber - semelhante àquele executado no vale do rio do Peixe por ordem da ferrovia - foi deflagrado em toda a região do planalto Contestado, nos vales dos rios Negro e Iguaçu. Desta feita, a Lumber Company, utilizando métodos similares aos empregados pela ferrovia, iniciou a expulsão dos posseiros na região do planalto. Ao todo, milhares de pessoas foram retiradas de suas terras. Nesse caso, também foi utilizada uma força armada privada, que realizava o trabalho indigesto de remoção ou assassínio das famílias de posseiros, "uma onda de horror varreu todo o território". ${ }^{11}$ 
A instalação da Lumber afetou de modo contundente a subsistência de milhares de moradores pobres da região do planalto. Além da expulsão de suas posses, aqueles que conseguiam se restabelecer padeciam com o desaparecimento ou a proibição da exploração das matas e ervais nativos, fatores essenciais para a sobrevivência daquelas pessoas.

Após a expulsão dos antigos moradores, a extração da madeira e a limpeza de toda a área, a companhia loteou e vendeu a terra para assentamento, realizado pelo estado do Paraná, a colonos poloneses e ucranianos, o que significou um processo de exclusão étnica, mediante a valorização da presença do imigrante em contraposição à presença da população nacional.

Esses contínuos atos de violência contra os caboclos e seu modo de vida, foram edificando o sentimento de injustiça, que resultou na adesão de milhares deles e de suas famílias às fileiras do movimento sertanejo.

A atuação das empresas estrangeiras em toda a região do Contestado e, especificamente, da Lumber Company no planalto Contestado, resultou em fator peremptório para a deflagração do conflito bélico, através do qual a população local reivindicou seus direitos e demonstrou claramente contra quem e o que estava lutando: os estrangeiros, o capital e as autoridades constituídas, explicitando assim a profunda racionalidade do movimento, que não representou uma odisseia de "fanáticos" ou "jagunços", mas a luta de pessoas pobres por aquilo que consideravam justo e seu por direito. Um bilhete encontrado no bolso de um rebelde morto em combate sintetiza os ideais de luta daquelas pessoas: "Nóis não tem direito de terras, tudo é para as gentes da Oropa". ${ }^{12}$ Um breve levantamento dos alvos da ofensiva sertaneja rebelde demonstra que o capital estrangeiro - a ferrovia e a Lumber - constavam entre seus principais objetivos estratégicos. Os sertanejos executaram incursões de ataque às estações da Estrada de Ferro São Paulo - Rio Grande, com a destruição de muitas delas e a interrupção da circulação das linhas regulares. Em Calmon, onde operava uma filial da Lumber Company, os rebeldes, além de atacarem as estações da ferrovia, incendiaram e destruíram completamente a serraria americana.

Em fins de janeiro de 1914, propagou a notícia da organização de um ataque que seria desferido contra a sede da Lumber, em Três Barras. Uma mensagem telegráfica, transmitida da sede da empresa ao chefe de polícia do Paraná, solicitou a proteção da localidade e, principalmente, das propriedades daquela companhia. Na capital paranaense, ocorreu o embarque imediato de um contingente do Regimento de Segurança do Paraná, que deveria reforçar as defesas e proteger a empresa. Aquele era um objetivo estratégico dentro da ampla ofensiva deflagrada pelos rebeldes no segundo semestre de 1914. Em 29 de setembro daquele ano, o ataque contra a sede da companhia foi executado, mas os rebeldes foram rechaçados pelas forças legais e por grande número de homens em armas mantidos pela própria empresa, seu Corpo de Segurança, que chegou a contar com quase trezentos homens. 
Em 02 de novembro de 1914, um piquete rebelde atacou a colônia Rio das Antas, uma estação da estrada de ferro e colônia de imigrantes, pequenos proprietários alemães e ucranianos assentados pela Lumber Company. Aquelas terras haviam sido alvo da expansão e predação fundiária da empresa, que as considerara devolutas. "Ali foram sumariamente espoliados de suas propriedades muitos sertanejos que há longos anos eram posseiros das devolutas terras $[\ldots]$ ".. ${ }^{13}$ Agora os sertanejos pretendiam recuperá-las e "com um mês de antecedência, Chiquinho Alonso [líder do piquete de ataque] mandara avisar que os verdadeiros e originais moradores daquela região estavam dispostos a voltar à força; os colonos que se retirassem ou seriam atacados". ${ }^{14}$

$\mathrm{O}$ avanço das pesquisas acerca do movimento do Contestado tornou explícito o hibridismo e a diversidade das motivações e dos objetivos, que variavam conforme a região da zona contestada em que os rebeldes se levantaram e dos setores sociais que aderiam ao movimento. No caso do planalto Contestado, a adesão ao movimento decorreu, em parte, da luta pelo cumprimento da sentença referente à disputa por limites entre Paraná e Santa Catarina e do embate entre posseiros, sitiantes e mesmo proprietários de maior vulto e a Lumber Company. O principal líder rebelde daquela região, Aleixo Gonçalves de Lima, lutava pelo cumprimento da sentença, e também mantinha com a Lumber ferrenha disputa por uma área de terras ao sul de Três Barras, registrada em cartório de Santa Catarina. A família Pacheco ocupou as terras, realizou o registro em cartório paranaense e, em seguida, as vendeu para a companhia americana. "Afirma-se que a invocação do nome de Aleixo fora bastante para levantar em armas centenas de sertanejos, muitos dos quais também expulsos de suas terras graças a manobras da empresa norte-americana $[\ldots] " .{ }^{15}$

Sendo assim, nos parece razoável a afirmação de que um dos motivos mais contumazes para a adesão dos sertanejos aos redutos do movimento sertanejo consistiu na sublevação contra as doações de terras a favor das empresas estrangeiras e sua expansão fundiária, processo que os afugentava das terras que consideravam suas por direito e justiça. Certamente a leitura feita pelos integrantes do movimento compreendia a expulsão das terras como parte de um processo mais amplo, que tinha origens políticas e classistas profundas: “[...] O governo da República toca os Filhos Brasileiros dos terrenos que pertence à nação e vende para o estrangeiro, nós agora estemo disposto a fazer prevalecer os nossos direitos". ${ }^{16}$

Como anteriormente aludido, o movimento sertanejo do Contestado reuniu diferentes motivações entre aqueles que ocuparam as trincheiras rebeldes. Machado assim as sintetiza:

Para os habitantes de Taquaruçu e Perdizes, locais de origem do movimento, a rebelião foi o caminho trilhado após a violência que os coronéis e o governo, em sua 
totalidade, haviam praticado contra o monge José Maria. Para os sitiantes e posseiros dos vales do Timbó, Tamanduá e Paciência, era um meio de combater a presença cada vez mais agressiva dos coronéis Fabrício Vieira e Arthur de Paulo e Souza, que desejavam estender suas propriedades e sua influência política sobre aquelas regiões. Para as oposições políticas formais aos chefes municipais de Curitibanos e Canoinhas, significava uma oportunidade ímpar de minar o poder do coronel Albuquerque e do Major Vieira. Para os antigos maragatos de todo o planalto, a "guerra santa" significava a volta à ativa e uma chance de desforra contra os pica-paus. ${ }^{17}$

Nesse complexo cenário multifacetado, podemos acrescentar, conforme demonstramos nas páginas anteriores, a luta no planalto Contestado contra o domínio e as injustiças deflagradas pela ferrovia e, principalmente, pela Lumber Company, especialmente no que tange à expulsão de milhares de posseiros dos vales dos rios Negro e Iguaçu.

Com base nas motivações dos integrantes do movimento, podemos atribuir a ele um caráter de conflito social, no qual os alvos dos rebeldes revoltosos demonstraram a racionalidade intrínseca do movimento: o capital estrangeiro; o domínio político e fundiário dos coronéis; a exclusão da população nacional em detrimento do assentamento de estrangeiros; a injustiça praticada por aqueles que ocupavam cargos nos governos municipais, estaduais e federal.

\section{O PÓS-GUERRA}

Após o cerco impingido aos rebeldes pela estratégia do general Setembrino de Carvalho, o movimento chega ao fim, em 1916. No entanto, a Lumber Company, uma das grandes responsáveis pelo incremento da tensão social e consequente deflagração do movimento sertanejo, permaneceu operando na região do planalto Contestado, desenvolvendo suas atividades predatórias por um longo período.

Posteriormente à retomada definitiva da região pelas forças legais, a empresa voltou a obter elevados lucros com a extração e exportação da madeira e erva mate. Os métodos utilizados para manter a próspera 'colheita do dólar' inspiram uma análise mais detida, uma reflexão acerca do legado negativo deixado pela empresa às gerações que se sucederam após sua instalação.

Os principais movimentos grevistas organizados pelos trabalhadores da Lumber Company acompanharam a grande onda de reivindicações operárias dos anos 1917-1920. O primeiro foi realizado no ano de 1917, e dois outros movimentos grevistas no ano de 1919. 
Especificamente em relação à greve de 1917, o jornal O Timoneiro do Norte noticiava a agitação operária em Três Barras na última semana daquele ano. O semanário chamava a atenção para as justas reivindicações dos trabalhadores e para suas dificuldades de sobrevivência, agravadas pela situação econômica vivenciada, decorrente da Primeira Guerra Mundial, que teve como consequência a depressão da indústria, e, principalmente, a carestia da vida, que aliada à estagnação dos salários resultara em greves em praticamente todo o Brasil. ${ }^{18}$

No caso particular da Lumber, podemos atentar para o fato de que o primeiro movimento grevista deflagrado por seus trabalhadores ocorreu pouco mais de um ano após o encerramento dos conflitos da Guerra do Contestado. Apesar das fontes ainda não fornecerem as conexões que evidenciariam tal relação, é absolutamente plausível supormos que alguns dos trabalhadores da companhia estiveram envolvidos nos conflitos detonados entre os anos de 1912 e $1916 \mathrm{ou}$, ao menos, possuíam parentes, amigos e conhecidos que integraram as forças sertanejas. Isso significa que estavam imbuídos do sentimento de injustiça e revanche que motivou as trincheiras do movimento rebelde, haja vista que alguns dos posseiros expulsos de suas terras, tanto pela ferrovia, quanto pela própria Lumber, mais tarde acabaram encontrando uma forma de subsistência mediante trabalho na madeireira.

Os dois momentos de mobilização dos trabalhadores da Lumber Company que tiveram maior vulto ocorreram no ano de 1919. O primeiro deles eclodiu em março daquele ano e tinha como objetivo principal o combate à atuação do médico da Lumber, Oswaldo de Oliveira, que também ocupava o cargo de deputado estadual. Ele foi hostilizado, acusado de perseguição política contra os trabalhadores, os quais exigiram sua saída do cargo de intendente do distrito de Três Barras.

As hostilidades contra o médico tinham duas possíveis vertentes. A primeira estava relacionada à sua participação nas disputas judiciais entre a Lumber e seus operários, fornecendo à empresa as 'provas' necessárias através de atestados médicos e avaliações parciais - para a redução do valor e/ou supressão de indenizações às vítimas. No entanto, como a legislação acerca dos acidentes de trabalho começou a vigorar apenas em janeiro de 1919, presumivelmente os trabalhadores ainda não haviam percebido a participação do médico nas ações judiciais em detrimento de seus interesses. Por outro lado, Oswaldo havia sido nomeado intendente distrital de Três Barras em 1917, em substituição à Dídio Augusto, ex-prefeito de Três Barras, paranaense e ativo militante a favor dos direitos dos trabalhadores, em oposição à companhia norteamericana. É possível que a mobilização estivesse conectada a esta substituição e a uma provável perseguição política promovida por Oswaldo contra Dídio.

Transcorridos dois meses, uma nova greve foi deflagrada. Aproveitando o momento favorável, os trabalhadores cruzaram os braços reivindicando 
diminuição na jornada de trabalho, a qual poderia chegar a dez horas diárias, bem como maior segurança, pois as péssimas condições de segurança no trabalho resultavam em elevada incidência de acidentes, que aumentava gradativamente. Novamente, a empresa perseguiu aqueles que tomaram parte ou apoiaram o movimento grevista. Nesse contexto, Dídio Augusto foi preso e enviado à cadeia de São Francisco do Sul - ponto final do ramal ferroviário que passava por Três Barras - pois, além do apoio que este oferecia ao movimento, representava os trabalhadores perante a diretoria da companhia - inclusive tendo realizado comícios durante a paralisação - e impetrou uma ação judicial contra a Lumber, razão pela qual sua deportação do distrito foi efetivada pelo subdelegado Theófilo Becker. ${ }^{19}$

Durante o período da greve, e mesmo no interregno entre os dois movimentos paredistas, o corpo de segurança da companhia e a polícia local impingiram um regime de terror àquela área. Essa postura violenta da empresa minou o movimento, o qual foi encerrado em 07 de junho de 1919:

E depois de tanta arbitrariedade e despotismo, perseguições e violências, os trabalhadores que não foram dispensados do serviço da companhia voltaram a trabalhar, sendo que grande é também o número de miseráveis que se retiraram para outras paragens. E o diretor Bischop, que dias antes dissera aos grevistas que ele paralisaria o serviço porque não precisava de nenhum operário, lá se ficou, a sugar o miserável escravo, recebendo uma fortuna por mês, rindose do fracasso, rindo-se dos exilados, dos deportados, dos perseguidos, dos miseráveis que revoltaram para exigirem menos exploração e mais um pouco de pão. ${ }^{20}$

Os movimentos grevistas deflagrados pelos trabalhadores da Lumber significaram uma nova forma encontrada pelos pobres da região para resistir ao domínio e à injustiça impostos pela empresa. A luta antes conduzida pelas armas e pela guerrilha era desenvolvida pelos trabalhadores de uma forma bastante eficiente: cruzando os braços.

Além da ampla repressão contra os trabalhadores, a direção da companhia, desde sua instalação, preocupou-se em cooptar lideranças políticas da região, tanto paranaenses, quanto catarinenses. Era fundamental para o bom andamento dos negócios manter aliados nos altos escalões das esferas governamentais. No entanto, no ano de 1920, ocorreu um abalo nas relações entre a companhia e o governo do estado de Santa Catarina, consequência de acirrada disputa política detonada no município de Canoinhas e no distrito de Três Barras, resultando no rompimento das relações políticas entre dois grupos do Partido Republicano local, um apoiado pelo então governador Hercílio Luz, e o outro pelos interesses econômicos da Lumber Company. 
A disputa iniciou-se no ano de 1919 e desenvolveu-se em torno de uma questão fundiária. A empresa e o governo do estado de Santa Catarina, não chegaram a acordo acerca da propriedade de uma área de terras chamada 'Pardos, localizada próxima à região de Três Barras. Além disso, as disputas políticas em torno do cargo de Superintende de Canoinhas elevaram a tensão dentre as partes envolvidas. Desde 1918, o Partido Republicano de Canoinhas estava cindido. Duas facções entraram em rota de colisão. Uma delas era chefiada pelo major Vieira, ex-superintendente municipal e deputado estadual. Esse grupo também recebeu o apoio de Oswaldo de Oliveira, chefe da política tresbarrense, deputado estadual, médico da Lumber Company e seu principal instrumento político. A outra facção era comandada por Otávio Xavier Rauen. Após discórdia resultante das eleições à Superintendência de Canoinhas, no ano de 1918, o govenador Hercílio Luz enviou um representante à região para 'conciliar' as duas facções. Isso significou o reconhecimento da vitória de Rauen. ${ }^{21}$

A 'conciliação' foi lida pelo grupo do major Vieira, Oswaldo de Oliveira e pela Lumber como humilhante derrota política e demonstração de rejeição por parte do governo estadual.

O novo superintendente - Rauen - iniciou um combate ferrenho a Oswaldo de Oliveira e seus aliados na região, atingindo, inclusive a Lumber Company.

Seguindo as diretrizes do "coronelismo", segundo as quais os principais cargos públicos eram preenchidos de acordo com os interesses do principal coronel local, normalmente o chefe do Partido Republicano e Superintendente Municipal, Rauen - sustentado por Hercílio Luz - promoveu mudanças contundentes na estrutura administrativa da região. A exoneração de Oswaldo de Oliveira do cargo de intendente distrital de Três Barras e, em seguida, do subdelegado local, Theófilo Becker, desarticularam as tramas de poder que ajudavam a sustentar os interesses da Lumber na região. Theófilo era o responsável pela condução dos inquéritos referentes aos acidentes de trabalho, cuja incidência ocasionava significativo impacto sobre o orçamento da companhia. Contando com a colaboração deste e do médico e intendente distrital, Oswaldo, a empresa conseguiu, utilizando todo tipo de embuste, amenizar o impacto econômico-financeiro resultante das questões trabalhistas.

Ao exonerar o subdelegado e nomear para seu cargo o tenente joinvilense da Força Pública de Santa Catarina, Francisco Arruda Câmara Junior, indivíduo externo à região e não alinhado aos interesses da empresa, Rauen e Hercílio atingiram diretamente a arquitetura política da companhia e, consequentemente, seus resultados econômico-financeiros. ${ }^{22}$

Imediatamente após sua exoneração, o ex-subdelegado, Theófilo, foi contratado como chefe do Corpo de Segurança da empresa. Poucas semanas depois, comandando um grupo de onze homens, entre eles operários da empresa 
e membros de sua guarda armada, Theófilo executou o novo subdelegado dentro das instalações do quartel local. O crime, além de expressar a crise instituída entre a empresa e o governo estadual, denota a supremacia do poder privado da companhia Lumber e seus métodos nada sutis, embora bastante eficientes. ${ }^{23}$

Nos anos e décadas subsequentes, a empresa prosseguiu com seu estratagema de expansão e domínio fundiário, aliado à repressão aos seus trabalhadores e a eliminação de qualquer empecilho ao bom andamento dos seus planos.

Entretanto, em 1940, um decreto de Getúlio Vargas encampou a Lumber Company. Com o processo de estatização da companhia, materializado pelo Decreto 2.436, de 22 de julho de 1940, a empresa foi incorporada ao Patrimônio da União e após a transição por um período de limbo administrativo, passou a ser gerenciada pelo exército brasileiro. Durante um período superior a dois anos, os trabalhadores da "ex-Lumber" não receberam seus salários, resultado de uma disputa administrativa em âmbito federal.

Anos mais tarde, através do Decreto 32.431, de 17 de março de 1953, o terreno e as instalações aonde a companhia desenvolveu suas atividades operacionais, foram transferidos para o Ministério da Guerra e, a partir de 1958, passaram a compor o Campo de Instrução Marechal Hermes - CIMH - ainda em atividade no município de Três Barras. O CIMH ocupa uma área de dez mil hectares e foi instituído pelo então Ministro da Guerra, General Henrique Teixeira Lott, a partir de uma área de dois mil hectares, anteriormente de propriedade da Lumber, bem como da desapropriação de outros oito mil hectares, atingindo "89 lotes de particulares, plenamente cultivados". ${ }^{24}$

Os problemas resultantes desse processo de desapropriação são muitos:

Desde a sua implantação, aquele campo militar se constitui em fator de intranquilidade e tensão social, porque os colonos expropriados não se conformaram ainda com a perda de suas terras. A situação foi agravada ainda quando da avaliação das terras pelos órgãos do Governo Federal, que além de estabelecer preço vil por hectare, o fizeram sem obedecer a qualquer critério. Lotes com as mesmas características e metragens foram avaliados por preços que oscilavam entre 50 centavos e 1 cruzeiro e 57 centavos o hectare, como se a qualidade da terra não fosse a mesma. ${ }^{25}$

Os contendores recorreram aos meios legais para reaver suas propriedades ou, ao menos, receber o valor justo pelas terras desapropriadas. Muitos se endividaram ao levantar os valores para quitação dos honorários advocatícios, e, ao receberam suas indenizações, perceberam que a inflação havia corroído os valores, apesar de corrigidos, impossibilitando a "aquisição de áreas outras, semelhantes àquelas das quais foram as famílias desalojadas". ${ }^{26}$ 
Na década de 1980, debates acerca da situação do campo de manobras foram travados no Congresso Nacional. Uma tentativa de políticos da região consistiu em requisitar a transferência do campo para outra área, onde não houvesse terras férteis e úteis para a produção agrícola. Outro argumento versava sobre os empecilhos promovidos pela presença da área militar, dificultando a expansão urbana de Três Barras e a comunicação desse município com a vizinha Papanduva.

A indefinição permanece. Parte dos descendentes dos antigos proprietários de áreas desapropriadas ainda contestam na Justiça o direito de reaver as terras, ou, por complementação do valor pago em função da desapropriação.

A gestão dos militares também é questionada, havendo acusações acerca da venda parcial da apreciável quantidade de madeira que povoa as matas do CIMH e, recentemente, em meados do mês de abril de 2012, adveio denúncia de que os militares vêm arrendando parte da área do campo para formação de lavouras de soja e milho, desvirtuando o objetivo original de oferecer treinamento às forças armadas. ${ }^{27}$

O debate acerca da presença e das ações do exército na região representa apenas o capítulo mais recente dessa longa história que, de um lado, é marcada pelo predomínio dos interesses privados em detrimento das necessidades públicas; pela ação do Estado como fomentador das tensões e da injustiça social e pelo ataque aos direitos da população mais pobre; e, do outro, pela história de resistência e luta que marcou profundamente toda a região.

Em Três Barras, na entrada do Campo de Instrução Marechal Hermes, uma placa expõe o lema do campo de manobras: "Nestas terras um dia contestadas o seu Exército adestra-se para defendê-las".

A indagação que perdura a um século permanece: defendê-las de quem e para quem?

\section{NOTAS}

1 A expressão Planalto Contestado foi forjada pelo professor Miguel Mundstock Xavier de Carvalho, ao analisar a devastação da floresta com araucária realizada pela Lumber Company. A expressão designa a área que corresponde ao atual planalto norte catarinense, desde o município de Mafra (divisa com Rio Negro) até Porto União e Caçador. A expressão é mais eficiente ao definir a região em tela, pois o atual município catarinense de Três Barras foi, até 1916, território paranaense contestado por Santa Catarina. CARVALHO, Miguel Mundstock Xavier de. Uma grande empresa em meio à floresta: a história da devastação da floresta com araucária e a Southern Brazil Lumber and Colonization (1870-1970). Tese (Doutorado em História), UFSC, Florianópolis, 2010, p. 200.

2 MACHADO, Paulo Pinheiro. Lideranças do Contestado: a formação das chefias caboclas (1912-1916). Campinas: Editora da Unicamp, 2004. 
3 MELlo E SOUZA, Antônio Cândido de. Os parceiros do Rio Bonito: estudos sobre o caipira paulista e a transformação dos seus meios de vida. São Paulo: Duas Cidades, 2001.

4 Ibidem, p. 81.

5 VINHAS DE QUEIROZ, Maurício. Messianismo e conflito social (a Guerra Sertaneja do Contestado: 1912-1916). Rio de Janeiro: Civilização Brasileira, 1966. p. 37.

${ }^{6}$ Em outros trabalhos, destacamos a amplitude e a importância dos conflitos oriundos das diferentes trocas entre os moradores do planalto. Ver: TOMPOROSKI, Alexandre Assis. "O pessoal da Lumber!" Um estudo acerca dos trabalhadores da Southern Brazil Lumber and Colonization Company e sua atuação no planalto norte de Santa Catarina, 1910 - 1929. Dissertação (Mestrado em História), UFSC, Florianópolis, 2006, especialmente p. 46 a 73.

7 THOMPSON, Edward Palmer. A formação da classe operária inglesa. v. I, II e III. Rio de Janeiro: Paz e Terra, 1987. THOMPSON, Edward Palmer. Costumes em comum. Estudos sobre a cultura popular tradicional. São Paulo: Companhia das Letras, 1998.

8 Jornal O Palmense. 05 nov. 1911. Biblioteca Pública do Estado do Paraná.

9 A Lumber construiu outra serraria em Calmon (SC).

${ }^{10}$ A partir da década de 1920, além da exploração da madeira em escala industrial, a Lumber também desenvolveu atividades ligadas ao beneficiamento e à exportação de erva mate. Além de explorar os vastos ervais nativos localizados nas terras recebidas na concessão ou posteriormente adquiridas, a Lumber também comprava a ilex de atravessadores locais, os quais acumulavam grandes quantidades adquiridas junto a pequenos produtores/coletores. A empresa incorreu em gastos com compra de erva mate de terceiros, bem como pela construção de barracões para armazenagem do produto. Com a utilização de seus próprios ramais e da ferrovia da Brazil Railway, a Lumber gerava baixos custos de transporte, o que lhe proporcionava vantagem sobre os demais empresários locais. Além da ferrovia, os rios da região eram caminhos para o escoamento da erva, por intermédio dos vapores "Três Barras" e "Porto Velho", embarcações de médio porte de propriedade da empresa. Tais embarcações exigiam um porto permanente, assim como trabalhadores especializados - ou ao menos fixos - para carga e descarga das embarcações e transporte do produto. In: Relatórios Mensais da Southern Brazil Lumber and Colonization Company. Balancete do mês de abril de 1917, p. 12. APESC, Arquivo Público do Estado de Santa Catarina, APESC.

${ }^{11}$ VINHAS DE QUEIROZ, op., cit., p. 73.

${ }^{12}$ ASSUMPÇÃO, Herculano T. A campanha do Contestado, v. 1. Belo Horizonte: Imprensa Oficial do Estado de Minas, 1917. p. 246.

${ }^{13}$ PEIXOTO, Demerval. Campanha do Contestado: episódios e impressões. Rio de Janeiro: 1916. p. 296.

${ }^{14}$ MACHADO, op. cit., p. 300.

${ }^{15}$ VINHAS DE QUEIROZ, op. cit., p. 166.

${ }^{16}$ PEIXOTO, op. cit., p. 74.

${ }^{17}$ MACHADO, op. cit., p. 259.

${ }^{18}$ O Timoneiro do Norte. Canoinhas. 29 jul. 1917. Ano I, n. 25. BPESC.

${ }^{19}$ Gazeta do Povo. Curitiba. 05 jun. 1919. n. 103. Biblioteca Nacional.

${ }^{20}$ A Plebe. São Paulo. 23 ago. 1919. Ano III, n. 27. Cópia micro filmada consultada no Arquivo Edgard Leuenroth, no IFCH-UNICAMP, em Campinas, SP. 
${ }^{21}$ O Democrata. Canoinhas. 29 fev. 1920. Ano II, n. 54. BPESC.

${ }^{22}$ Processo Crime por Homicídio do Tenente Francisco Arruda Câmara Junior. Réu: Theófilo Becker e outros. Canoinhas, 1920. AHMC.

${ }^{23}$ Este crime, suas razões e suas consequências políticas foram pormenorizadamente analisados e descritos no texto da tese de doutorado. TOMPOROSKI, Alexandre Assis. O polvo e seus tentáculos. A Southern Brazil Lumber and Colonization Company e as transformações impingidas ao planalto contestado, 1910-1940. Tese (Doutorado em História), UFSC, Florianópolis, 2013.

${ }^{24}$ Diário do Congresso Nacional (Seção I), p. 907. 20 mar. 1980.

${ }^{25}$ Ibidem, p. 908.

${ }^{26}$ Diário do Congresso Nacional (Seção I), p. 5832. 03 ago. 1982

${ }^{27}$ Correio do Norte. Canoinhas. 13 abr. 2012. Ano 65. n. 3033.

Artigo recebido em dezembro de 2012. Aceito em dezembro de 2012. 